\title{
Injury Induces a Change in the Functional Characteristics of Cells Recovered from Equine Tendon
}

\author{
Rina KIHARA $^{1}$, Yoshinori KASASHIMA ${ }^{2,4}$, Katsuhiko ARAI ${ }^{3}$ and Yasunori MIYAMOTO ${ }^{1 *}$ \\ ${ }^{1}$ Division of Life Sciences, Graduate School of Humanities and Sciences, Ochanomizu University, Tokyo 112- \\ 8610, ${ }^{2}$ Clinical Science and Pathobiology Division, Equine Research Institute, Japan Racing Association, \\ Utsunomiya, Tochigi 320-0856, ${ }^{3}$ Department of Tissue Physiology, Tokyo University of Agriculture and \\ Technology, Fuchu, Tokyo 183-8509, Japan, ${ }^{4}$ Department of Veterinary Clinical Sciences, The Royal \\ Veterinary College, Hawkshead Lane, North Mymms, Hatfield, Herts, AL9 7TA, U.K.
}

Injury initiates a repair process characterized by influx of fibroblasts and the rapid formation of fibrous scar tissue and subsequent tissue contraction. The response to injury and behavior of the different tendon fibroblast populations, however, has been poorly characterized. We hypothesized that the fibroblasts recovered from tendon with acute injury would exhibit different cell properties relating to adhesion, migration and tensegrity. To test this hypothesis we evaluated the ability of fibroblasts recovered from normal and injured equine superficial digital flexor tendons (SDFTs). The injured tendon-derived cells showed greater contraction of the collagen gel but poorer adhesion to pepsin-digested collagen, and migration over extracellular matrix proteins compared to normal SDFT-derived fibroblasts. Thus, the cells present within the tendon after injury display different behavior related to wound healing.

Key words: fibroblast, injury, tendon
J. Equine Sci.

Vol. 22, No. 3

pp. 57-60, 2011
Tendon injury is one of the common musculoskeletal problems suffered by race horses, and it is a significant cause of loss of racehorses throughout the world [1-4]. The predominant site of injury is the superficial digital flexor tendon (SDFT) $[5,6]$. The histopathologic symptoms at the onset of tendon injury include hemorrhage and inflammation. Injury initiates a repair process which is performed by internal tendon fibroblasts, epitenon and endotenon tendon fibroblasts, and invasive cells from the surrounding sheath and synovium [7]. Some of the tendon fibroblasts are migrated into the granulation tissue generated in the injured region, and the fibroblasts start to proliferate $[6,8]$. The proliferated fibroblasts are involved in the restoration of injured areas, synthesis of collagen, and the rapid formation of fibrous scar tissue and subsequent tissue contraction [9, 10]. In the lesions, proliferated fibroblasts observed

This article was accepted August 12, 2011

*Corresponding author. e-mail: miyamoto.yasunori@ocha.ac.jp are morphologically different from normal tendon fibroblasts, and the biochemical characteristics of the fibroblasts seem to be different from those of normal SDFT fibroblasts [11]. However, the behavior of the proliferated tendon fibroblasts related to wound repair has been poorly characterized. Additionally, transforming growth factor (TGF)- $\beta$ has been reported to affect various properties of fibroblasts, such as collagen expression and differentiation into myofibroblasts, and is involved in the contraction of injured tissue $[9,12]$.

In this study, to characterize the properties of cells derived from equine SDFT with acute injury, we compared properties of collagen gel contraction, cell adhesion onto collagen, and cell migration in normal and injured SDFT-derived cells. In addition, we also examined effects of TGF- $\beta$ on the properties in injured SDFT-derived cells.

Normal SDFTs obtained from the two Thoroughbred racehorses with no symptom and history of tendon injury. On the other hand, injured tendons obtained from two 
Thoroughbred racehorses on 7 days just after occurrence of typical acute tendon injury with hemorrhage. Normal and injured SDFT-derived primary cells were obtained by grow-out from explants of such normal and acutely injured equine SDFT, respectively as described previously [12]. These tendon-derived fibroblasts were used at passages 5 to 15 .

First, collagen gel contraction assay, which is a model system for the investigation of scar contraction in wound repair, was performed against normal and injured SDFT-derived cells using flat bottom 96-well plates (MS-3496F, Sumitomo Bakelite, Co., Tokyo, Japan) as described previously [13]. A collagen solution was mixed up at 1:1 ratio with $2 \mathrm{X}$ Dulbecco's modified Eagle's medium (DMEM) and acid-soluble collagen type I (3 mg/m , Cellmatrix Type I-A, Nitta Gelatin Inc., Osaka, Japan). The two volumes of mixed collagen solution were further mixed up with one volume of TGF- $\beta$ (T7039, SIGMA-Aldrich, St. Louis, MO) treated or un-treated cell suspension. Hundred microliter of the cell-collagen suspension with $1.3 \times 10^{4}$ cells was incubated for $24 \mathrm{hr}$ at $37^{\circ} \mathrm{C}$. After incubation, each gel area was measured. The results showed that the area of collagen gel with injured SDFT-derived cells was significantly contracted by $74 \%$ of area with normal SDFT-derived cells after $24 \mathrm{hr}$ incubation (Fig. 1). TGF- $\beta$ treatment enhanced the gel contraction up to $25 \%$ of gel area with injured SDFT-derived cells and $37 \%$ of that with normal cells, respectively (Fig.1). These results indicated that injured SDFT-derived cells have higher gel contraction ability than normal cells and these cells were kept responsive to TGF- $\beta$. This result suggests that cells in the lesion may have higher contraction properties than normal and tend to form scar in an earlier stage than normal cells and induce incomplete repaired lesions.

Next, we examined cell adhesion properties of SDFTderived cells on acid-soluble and pepsin-digested collagen. Cell adhesion assay was performed using flat bottom 96-well plates coated with the indicated concentration of pepsin-digested type I collagen (Cellmatrix Type I-P, Nitta Gelatin Inc.). The tendon derived cells $\left(0.4 \times 10^{5}\right.$ cells $\left./ \mathrm{m} l\right)$ in DMEM with 1,000 mg glucose /l (SIGMA-Aldrich) were incubated for $1 \mathrm{hr}$ at $37^{\circ} \mathrm{C}$. After the incubation, adherent cells were fixed with $1.1 \%(\mathrm{v} / \mathrm{v})$ glutaraldehyde solution and stained with crystal violet solution. The amount of the adherent cells was quantified by absorbance at $595 \mathrm{~nm}$. The assay showed cell adhesion of the injured SDFTderived cells onto acid-soluble collagen was similar to

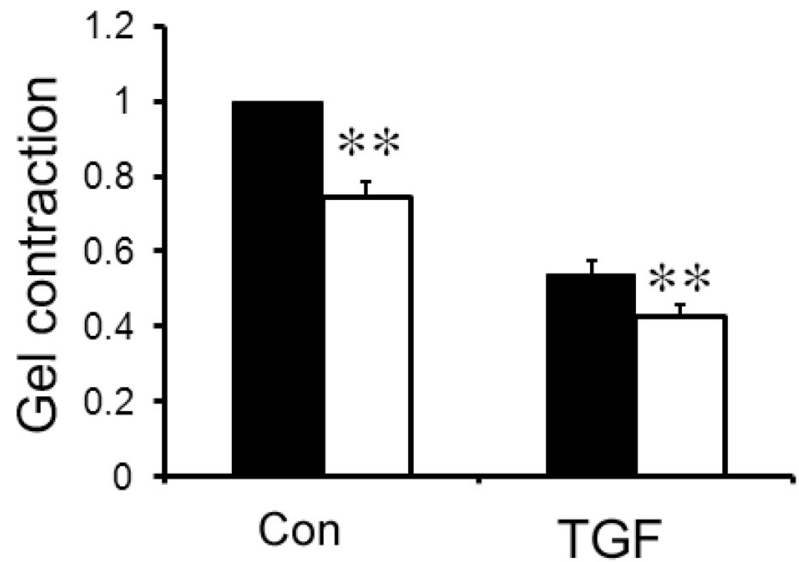

Fig. 1. Collagen gel contraction of injured superficial digital flexor tendon (SDFT)-derived fibroblast cells.

The gels were further incubated for $24 \mathrm{hr}$ at $37^{\circ} \mathrm{C}$ after the gels were formed with non-treated or TGF- $\beta(1.0 \mathrm{ng} /$ $\mathrm{m} l$ )-treated normal SDFT- (solid bar) or injured SDFT(blank bar) derived cells. Results showed the area after $24 \mathrm{hr}$ of the collagen gel of the normal SDFT-derived cell as one by a relative value. Results are the means of 8 experiments \pm 1 SEM. $* * \mathrm{p}<0.01$ in two-sided $t$ test.

that of the normal cells (data not shown), but cell adhesion of the injured SDFT-derived cells onto pepsin-digested collagen was significantly lower than the normal cells (Fig. 2). In injured tendon, activities of matrix metalloproteinases (MMPs) have been reported to be enhanced and MMPs facilitate degradation of extracellular matrix molecules including collagen $[6,14]$. Taken together, adhesive ability of fibroblasts on digested collagen in the lesion may be weaker compared with that of normal cells.

Deposition of cell adhesion molecules, fibronectin and vitronectin from serum has been reported in the granulation tissue $[15,16]$. Some of tendon fibroblasts migrate into the granulation tissue. To examine the effect of these adhesive proteins on injured SDFTderived cells, cell migration assay of injured and normal cells was performed on fibronectin and vitronectin using chemotaxis chamber with $8-\mu \mathrm{m}$ pore polycarbonate filters (Kurabo industrials Ltd., Osaka, Japan). Each filter was coated with fibronectin or vitronectin $(5 \mu \mathrm{g} / \mathrm{m} l)$, which was purified from human serum as described previously $[17,18]$, for $1 \mathrm{hr}$ at $37^{\circ} \mathrm{C}$. The TGF- $\beta$ treated or non-treated cells $\left(1.6 \times 10^{5}\right.$ cells $/$ chamber) in DMEM were incubated for $2 \mathrm{hr}$ (in fibronectin-coated chamber) or $5 \mathrm{hr}$ (in vitronectincoated chamber) at $37^{\circ} \mathrm{C}$. After removal of the un- 


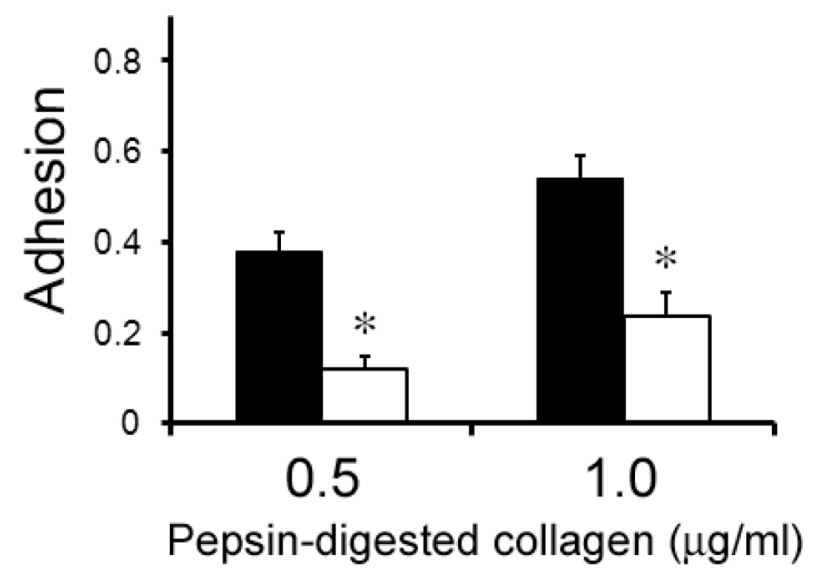

Fig. 2. Cell adhesion of normal or injured SDFT-derived cells onto pepsin-digested collagen.

Normal (solid bar) or injured SDFT- (blank bar) derived cells were plated onto pepsin-digested collagen and cultured for $1 \mathrm{hr}$ at $37^{\circ} \mathrm{C}$. The attached cells were stained with crystal violet and quantified by absorbance at $595 \mathrm{~nm}$. Each result shows relative value normalized with that of $7.5 \mu \mathrm{g} / \mathrm{m} l$ collagen as 1 . Error bars show standard error. ${ }^{*} \mathrm{p}<0.05$ in two-sided $t$ test.

migrated cells, the migrated cells were counted by microscopy. Number of the migrated injured SDFTderived cells was decreased at about $50 \%$ on fibronectin and at about $80 \%$ on vitronectin, compared with number of normal cells (Fig. 3). TGF- $\beta$ treatment drastically decreased the migration abilities on both proteins (Fig. 3). These results showed the migration ability of the injured SDFT-derived cells are declined than that of the normal cells and the ability of the injured SDFT-derived cells is decreased by TGF- $\beta$ treatment in the same manner as the normal cells. These results suggest migration ability of injured SDFTderived cells in the lesion may be reduced in vivo.

TGF- $\beta$ is known to function as a biosynthetic modulator of the extracellular matrix. TGF- $\beta$ is highly expressed after wounding and influences wound healing at least partly by the induction of collagen synthesis [9]. In addition, TGF- $\beta$ promotes collagen contraction and inhibits migration of vascular smooth muscle cells [19]. Our results are consistent with these observations, and the effect of TGF- $\beta$ on the migration and collagen contraction was retained by the cells recovered after injury.

In conclusion, we have demonstrated that the cells recovered from injured tendon display different properties compared to the cells recovered from
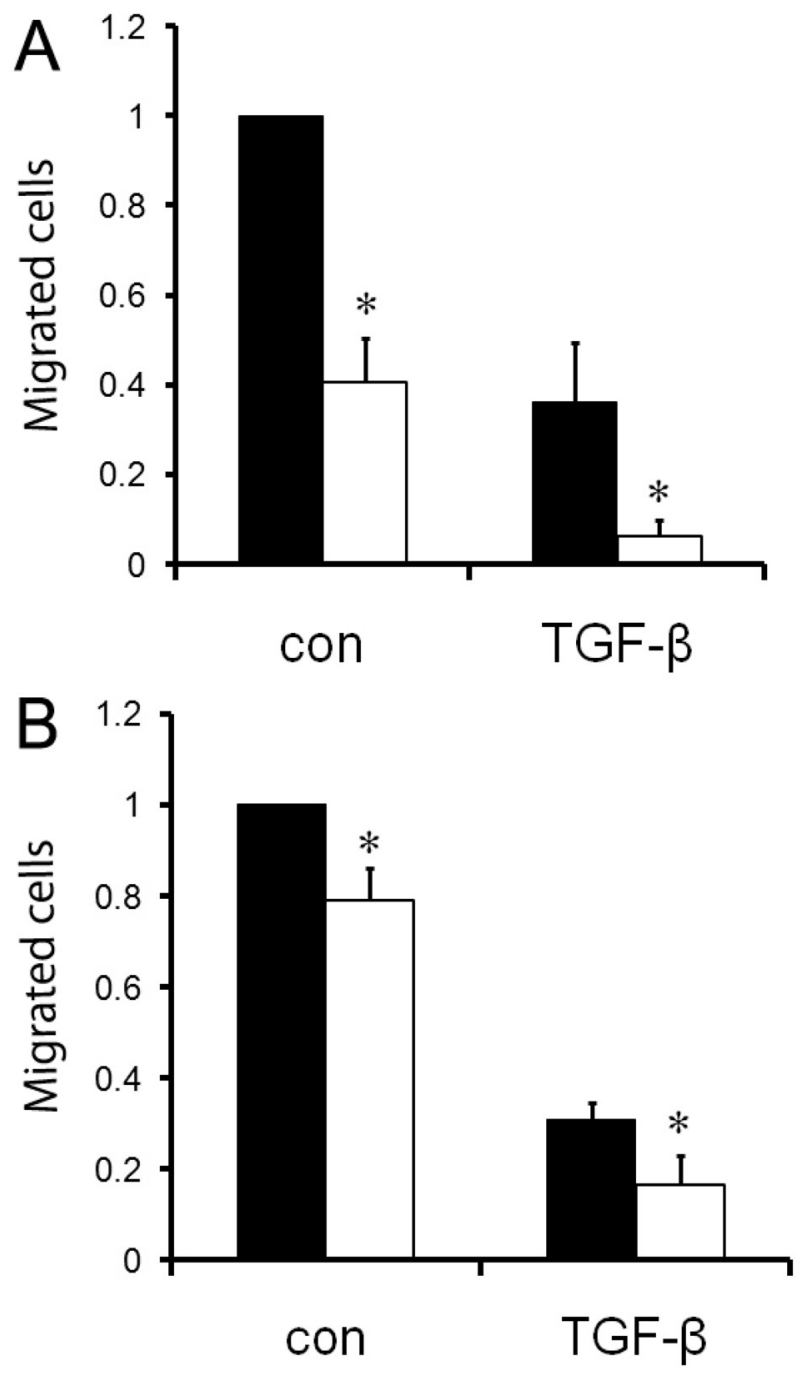

Fig. 3. Cell migration assay of normal or injured SDFT-derived cells on fibronectin or vitronectin.

Normal (solid bar) or injured SDFT- (blank bar) derived cells were plated onto fibronectin (A)- or vitronectin (B)coated well chambers and cultured for $2 \mathrm{hr}$ on fibronectin or $5 \mathrm{hr}$ on vitronectin at $37^{\circ} \mathrm{C}$. To examine the effect of TGF- $\beta$ on injured SDFT-derived cells, the cells were pretreated with TGF- $\beta 1(1.0 \mathrm{ng} / \mathrm{m} l)$. Each result shows the number of migrated normal SDFTderived cells as 1 by a relative value. Error bas shows standard error. ${ }^{*} \mathrm{p}<0.05$ in two-sided $t$ test.

normal tendon and that this phenotypic difference is maintained when in primary cell cultures. The enhancement of collagen gel contraction ability with a reduction in cell adhesion and migration suggest that injured tendon derived cells may be inferior in comparison to normal tendon cell population in some 
of the events associated with wound repair, which may lead to defective healing and recurrent cycles of reinjury. These differences may arise either through a change of cell behavior or the presence of an innately different cell type, which would inform new putative therapeutic targets.

\section{References}

1. Kasashima, Y., Takahashi, T., Smith, R.K., Goodship, A.E., Kuwano, A., Ueno, T., and Hirano, S. 2004. Prevalence of superficial digital flexor tendonitis and suspensory desmitis in Japanese Thoroughbred flat racehorses in 1999. Equine Vet. J. 36: 346-350.

2. Lam, K.H., Parkin, T.D., Riggs, C.M., and Morgan, K.L. 2007. Descriptive analysis of retirement of Thoroughbred racehorses due to tendon injuries at the Hong Kong Jockey Club (1992-2004). Equine Vet. J. 39: 143-148.

3. Williams, R.B., Harkins, L.S., Hammond, C.J., and Wood, J.L. 2001. Racehorse injuries, clinical problems and fatalities recorded on British racecourses from flat racing and National Hunt racing during 1996, 1997 and 1998. Equine Vet.J. 33: 478-486.

4. Peloso, J.G., Mundy, G.D., and Cohen, N.D. 1994. Prevalence of, and factors associated with, musculoskeletal racing injuries of thoroughbreds. J. Am. Vet. Med. Assoc. 204: 620-626.

5. Goodship, A.E., Birch, H.L., and Wilson, A.M. 1994. The pathobiology and repair of tendon and ligament injury. Vet. Clin. North Am. Equine Pract. 10: 323-349.

6. Batson, E.L., Paramour, R.J., Smith, T.J., Birch, H.L, Patterson-Kane, J.C., and Goodship, A.E. 2003. Are the material properties and matrix composition of equine flexor and extensor tendons determined by their functions? Equine Vet. J. 35: 314-318.

7. Sharma, P., and Maffulli, N. 2006. Biology of tendon injury: healing, modeling and remodeling. J. Musculoskelet. Neuronal Interact. 6: 181-190.

8. Jasti, A.C., Wetzel, B.J., Aviles, H., Vesper, D.N., Nindl, G., and Johnson, M.T. 2001. Effect of a wound healing electromagnetic field on inflammatory cytokine gene expression in rats. Biomed. Sci. Instrum. 37: 209-214.

9. Klein, M.B., Yalamanchi, N., Pham, H., Longaker,
M.T., and Chang, J. 2002. Flexor tendon healing in vitro: effects of TGF-beta on tendon cell collagen production. J. Hand Surg. [Am.] 27: 615620.

10. Maffulli, N., Ewen, S.W., Waterston, S.W., Reaper, J., and Barrass, V. 2000. Tenocytes from ruptured and tendinopathic achilles tendons produce greater quantities of type III collagen than tenocytes from normal achilles tendons. An in vitro model of human tendon healing. Am. J. Sports Med. 28: 499-505.

11. Mosier, S.M., Pomeroy, G., and Manoli, A. 2nd. 1999. Pathoanatomy and etiology of posterior tibial tendon dysfunction. Clin. Orthop. Relat. Res. 365: 12-22.

12. Arai, K., Kasashima, Y., Kobayashi, A., Kuwano, A., and Yoshihara, T. 2002. TGF-beta alters collagen XII and XIV mRNA levels in cultured equine tenocytes. Matrix Biol. 21: 243-250.

13. Gullberg, D., Tingstrom, A., Thuresson, A.C., Olsson, L., Terracio, L., Borg, T.K., and Rubin, K. 1990. Beta 1 integrin-mediated collagen gel contraction is stimulated by PDGF. Exp. Cell Res. 186: 264-272.

14. Clutterbuck, A.L., Harris, P., Allaway, D., and Mobasheri, A. 2010. Matrix mettalloproteinases in inflammatory pathologies of the horse. Vet. J. 183: 27-38.

15. Kusubata, M., Hirota, A., Ebihara, T., Kuwaba, K., Matsubara, Y., Sasaki, T., Kusakabe, M., Tsukada, T., Irie, S., and Koyama, Y. 1999. Spatiotemporal changes of fibronectin, tenascin-C, fibulin-1, and fibulin-2 in the skin during the development of chronic contact dermatitis. J. Invest. Dermatol. 113: 906-912.

16. Sobel, R.A., Chen, M., Maeda, A., and Hinojoza, J.R. 1995. Vitronectin and integrin vitronectin receptor localization in multiple sclerosis lesions. J. Neuropathol. Exp. Neurol. 54: 202-213.

17. Hayashi, M., and Yamada, K.M. 1982. Divalent cation modulation of fibronectin binding to heparin and to DNA. J. Biol. Chem. 257: 5263-5267.

18. Yatohgo, T., Izumi, M., Kashiwagi, H., and Hayashi, M. 1988. Novel purification of vitronectin from human plasma by heparin affinity chromatography. Cell Struct. Funct. 13: 281-292.

19. Mii, S., Ware, J.A., and Kent, K.C. 1993. Transforming growth factor-beta inhibits human vascular smooth muscle cell growth and migration. Surgery 114: 464-470. 